\title{
Current Concepts in Diabetic Neuropathy
}

\author{
Wahaj D. Ahmad, M.D. \\ Fayetteville, North Carolina
}

DOI: http://dx.doi.org/10.5915/22-1-13527

\begin{abstract}
Diabetic neuropathies are classified, for the sake of convenience, into four groups. First are the distal symmetrical variety that may be predominantly motor or predominantly sensory. Second are the mononeuropathy syndromes of cranial or somatic nerves. Third are the automatic group and finally, any combination of two or three varieties. Etiopathology of these neuropathic syndromes takes into consideration the biochemical alterations and ischemic changes. The most recent understanding of the role of aldose reductase in the polyol pathway is presented briefly, as is, in the hyperglycemic state, sorbitol accumulation, which resuls in the decrease of ATPase activity and slowing of nerve conduction. In the treatment of diabetic neuropathies, aldose reductase inhibitors are being used in many centers and their release for general use is anxiously awaited.
\end{abstract}

Key words: Diabetic neuropathy, aldose reductase, sorbitol, aldose-reductase inhibitors

Diabetic neuropathy is a fairly common condition and has been recognized for more than a century. ${ }^{1,2}$ Our understanding of its causation, however, is still incomplete. Nevertheless, recent biochemical advances seem promising and are very likely to influence our approach to the treatment of this condition.

Since there are many neuropathy syndromes associated with diabetes mellitus, it is more appropriate to speak of "diabetic neuropathies" rather than neuropathy. In considering the association of these two conditions, it should be recognized that the neuropathy may sometimes make its clinical appearance even before diabetes manifests itself. ${ }^{3}$ This raises the question of whether neuropathy is a part of diabetes or a complication thereof.

There are many ways to classify diabetic

From the Neurology Section, Department of Medicine V.A. Medical Center

2300 Ramsey Street

Fayetteville, NC 28301

Reprint Requests: Wahaj D. Ahmad, M.D.

Neurology Section, Department of Medicine

V.A. Medical Center

2300 Ramsey Street

Fayetteville, NC 28301 neuropathies. ${ }^{4}$ The following grouping of these conditions is given only for convenience of discussion:

I) Distal symmetrical polyneuropathy (sensorimotor)

a) Painful type: predominantly sensory, generally affecting the lower extremities.

b) Painless type: predominantly motor, generally affecting the distal parts of the extremities.

II) Mononeuropathy syndromes

a) Mononeuropathy (any somatic nerve, eg, median, femoral or peroneal)

b) Cranial mononeuropathy (eg, 3rd, 4th, or 6th nerves)

c) Mononeuropathy multiplex.

d) Proximal mononeuropathy (Diabetic amyotrophy)

III) Autonomic neuropathy

There are many autonomic neuropathy syndromes. The following list is by no means complete.

a) Gastro-intestinal

1) Esophageal dysfunction

2) Gastro-paresis

3) Diabetic diarrhea

b) Genito-urinary

1) Cysto-paresis [with overflow incontinence]

2) Male impotence

c) Cardiovascular

1) Postural hypotension

2) Arrhythmias 
d) Pupilary and sweating abnormalities

IV) Mixed Neuropathies, ie, any combination of two or more of the above syndromes.

\section{Clinical Features}

It is not our purpose to review the clinical features of all the the conditions mentioned above except to mention some of the less common or less well understood conditions. Numbness, neuritic pain and dysesthesias are easily recognized.

A mononeuropathic syndrome is frequently heralded by pain and paresthesia; the important thing to remember is that the prognosis is uniformally good, although recovery may take two years or more. Thoracic neuropathy or radiculopathys presents with acute chest pain or upper abdominal pain. Its early recognition may prevent an unnecessary surgical procedure. Truncal polyneuropathy ${ }^{6}$ and polyradiculopathy ${ }^{7,8}$ have also been described in diabetics.

Diabetic amyotrophy ${ }^{9}$ is the term applied to the syndrome of acute onset of pain and weakness in one or both lower extremeties, especially the thigh muscles such as the quadriceps and psoas. Rapid wasting develops in the quadriceps and sometimes other muscles such as the glutei, hamstrings, etc. There is gradual recovery over a period of one to two years. The facts that (1) Hugh Garland described this syndrome first as diabetic myelopathy, ${ }^{10}$ later corrected to amyotrophy," and that (2) the clinical findings of these patients are not limited to the muscles supplied by the femoral nerves has resulted in multiple names. These include "symmetrical proximal motor neuropathies", 12 "femoral neuropathy", ${ }^{13}$ etc. This also illustrates the difficulty in placing this syndrome in the usual classification. The exact pathology of this particular condition is not understood.

Diabetic neuropathic cachexia ${ }^{14}$ is the condition of diffuse motor neuropathy with generalized wasting of muscles and some pain. It is generally considered a self-limited condition with good prognosis.

Pain in these patients may not necessarily be of neuropathic type, but may be due to degenerative arthritis.

When sensory neuropathy has been present for a prolonged time, complications such as Charcot's arthropathy, due to decreased nocifensive reflex, may develop.

Autonomic neuropathies are found in 20 to $40 \%$ of diabetic patients if looked for carefully. ${ }^{15}$ Pupilary and sweating abnormalities are usually of no serious consequence other than the production of ArgyllRobertson - like pupil, causing difficulties in differential diagnosis. Postural hypotension and "silent" myocardial infarction 16 or arrythmias" are clearly worthy of attention. Nocturnal episodic diarrhea of the diabetics is known to respond to an- tibiotics $^{18}$ and gastro - paresis is helped by metoclopramide. ${ }^{19}$ Impotence is reported in as many as $50 \%$ of the diabetic male population. ${ }^{20}$ For diagnosis and treatment, a very careful history, especially of erectile and ejaculatory functions, is essential.

\section{Pathology and Pathogenesis}

The diabetic changes observed in axons, myelin, and Schwann cells are nonspecific. There has been a debate over whether segmental demyelination or axonal degeneration is the primary event. More recently, electroneuromyographic studies have suggested that injury to the axon is the primary structure event. ${ }^{21}$

The pathogenetic mechanisms that result from hyperglycemia have been studied for many decades. ${ }^{22}$ For details, Low's description in "Muscle and Nerve" ${ }^{23}$ may be consulted.

It may be useful at this juncture to recapitulate very briefly the anatomic physiology and biochemistry. A nerve fiber consists of three elements:
a) Axon
b) Myelin Sheath
c) Schwann cells.

The myelin sheath is composed of fatty structures and some proteins. It is wrapped around the axon longitudinally in an "onion skin" fashion. One Schwann cell is located in each internode (the nodes of Ranvier divide the entire length of the fiber into many internodes of various lengths). Saltatory conduction of the nerve impulse depends upon the integrity of the myelin sheath. Axonal filaments have their own flow of nutritive materials running from the cell body to the termination of the axon.

The energy required to maintain the nerve conduction velocity (physiological measure of the integrity of nerve function $)^{24}$ depends upon the ATPase activity in the nerve fiber. Also, myoinositol, a glucose isomer, helps in electrolyte and aminoacid transport in the nerve fibers.

In normal glucose metabolism hexokinase activity is the major activity in the nerve fiber, whereas aldose-reductase activity of the polyol pathway has a minor role. In the diabetic nerves, however, due to sustained high levels of glucose, the hexokinase activity becomes saturated and aldose-reductase activity is increased. As seen in the equation below, aldosereductase converts glucose, in the presence of $\mathrm{NADPH}$, into sorbital, which in turn is converted to fructose by dehydrogenase.

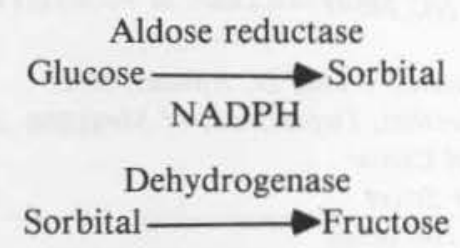


This result in an accumulation of sorbital and fructose, which in turn decreases myoinositol; hence, activity of sodium-potassium-ATPase is decreased. Required energy consumption in the nerve fiber is reduced with a resultant decrease in the nerve conduction velocity. ${ }^{23}$

Involvement of vasa nervorum due to diabetic microangiopathy ${ }^{2 s}$ producing ishemia will decrease the turnover of myelin and slow down the axonal transport system. ${ }^{26} \mathrm{It}$ is conceivable that all these factors, singly or in combination, acting over a long period of time may result in structural damage to the nerves in diabetics.

\section{Treatment}

From the above description, it seems plausible that reducing the activity of aldose-reductase may improve or prevent neuropathy in diabetics. ${ }^{27}$ During the last five years, various diabetic centers have attempted trials of aldose-reductase inhibitors, both experimentally and in patients with diabetic neuropathy. Although the results have not been uniformly impressive, this line of treatment appears to have clear promise for the control of diabetic neuropathy in the future.

Treatment of painful neuropathy with drugs such as diphenyl hydantoin and carbamazepine is well established. Anti-depressive medications, such as amitriptyline alone or in combination with a phenothiazine, have been used more recently for the control of pain. ${ }^{28,29}$ As far as the use of narcotic analgesics is concerned, caution should be exercised as these conditions generally have good prognosis. We anxiously wait for the release of aldose-reductase inhibitors such as sorbinil or tolrestat for the treatment of diabetic neuropathy.

\section{References}

1. Martin MM. Diabetic neuropathy, a clinical study of 150 cases. Brain 1953; 76:594.

2. Pavy FW. Introductory address to the clinical aspects of glycosuria. Lancet 1885; 2:1033-1085.

3. Ellenberg M. Diabetic complications without manifest diabetes: Complications as presenting symptoms. JAMA 1963; 183:926.

4. Dyck PJ, Jarnes J, O'Brien PC. Diagnosis, staging, and classification of diabetic neuropathy and association with other complications. In: Dyck PJ, Thomas PK, Asbury AK, Winegrad AI, Porte D. (Eds.) Diabetic Neuropathy. Philadelphia: WB Saunders Company; 1987: 36-44.

5. Harati Y, Niakan E. Diabetic thoracoabdominal neuropathy: Cause for chest and abdominal pain. Arch Intern Med 1986; 146:1493 - 1494.

6. Ellenberg M. Diabetic truncal mononeuropathy - a new clinical syndrome. Diabetes Care 1978; $1: 10-13$.
7. Boulton AJ, Agus I, Ayyar DR, Weiss DR. Diabetic thoracic polyradiculopathy presenting as abdominal swelling. $\mathrm{Br}$ Med $\mathrm{J} 1984 ; 289$ : 798-799.

8. Waxman SG, Sabin TD. Diabetic truncal polyneuropathy. Arch Neurol 38: 46-47.

9. Chokroverty S, Reyes MG, Rubino FA, Tonaki $\mathrm{H}$. The syndrome of diabetic amyotrophy. Ann Neurol 1977; 2: 181-194.

10. Garland H, Taverner D. Diabetic myelopathy. Br Med J 1953; 1:1405.

11. Garland H. Diabetic amyotrophy. Br Med J 1955; 2: 1287-1290.

12. Harati Y. Diabetic peripheral neuropathies. Ann Intern Med 1987; 107: 546-559.

13. Calverly JR, Mulder DW, Femoral neuropathy. Neurology (Minn.) 1960; 10: 962-969.

14. Ellbenberg M. Diabetic neuropathic cacexia. Diabetes 1974; 23: 418-423.

15. Ewing DJ, Clarke BF. Diabetic autonomic neuropathy, present insights and future prospects. Diabetes Care 1986; 9: 648-665.

16. Faerman I, Faccio E, Milei R, et al. Autonomic neuropathy and silent mycardial infarction in diabetic patients: Histologic evidence of their relationship. Diabetes 1977; 26: 1147-1158.

17. Ewing DJ, Campbell IW, Clarke BF. Heartrate changes in diabetes mellitus. Lancet 1981; 1 : 183-186.

18. Snape WJ, Battle WM, Schwartz SS, Braunstein SN, Goldstein HA, Alavi A. Metoclopramide to treat gastro-paresis due to diabetes mellitus: A double-blind controlled trial. Ann Med 1982; 96 : 444-446.

19. Green PA, Berge KG, Sprague RG. Control of diabetic diarrhea with antibiotic therapy. Diabetes 1968; 17: 385-387.

20. Schoffling K, Federlin K, Ditchuneit $\mathrm{H}$, et al. Disorders of sexual function in male diabetics. Diabetes 1963; 12: 519.

21. Martinez A Cruz. Diabetic neuropathy: Topography, general electrophysiologic features, effect of ischemia on nerve evoked potential, and fequency of entrapment neuropathy. Electromygr Clin Neurophysiol 1986; 26: 283-295.

22. Ward JD. Diabetic Neuropathies - Current concepts in prevention and treatment. Drugs 1986; 32: 279-289.

23. Low PA. Recent advances in the pathogenesis of diabetic neuropathy. Muscle Nerve 1987; 10: 121-128.

24. Gilliat RW, Willison R. Peripheral nerve conduction in diabetic neuropathy. J Neurol Neurosurg and Psychiatry 1962; 25: 11-18.

25. Williams E, Timperly WR, Ward JD, Duckworth T. electron microscopic studies of vessels in diabetic peripheral neuropathy. J Clin Pathol 1980; 462-470. 
26. Jakobsen J, Sidenius P. Decreased axonal transport of structural proteins in streptozotocin diabetic rats. J Clin Invest 1980; 66: 292-297.

27. Judzewitsch RG, Jaspan JB, et al. Aldosereductase inhibition improves nerve conduction velocity in diabetic patients. N Engl J Med 1983 308: 119-125.

Schultz TA, Wallin, JD. Peripheral diabetic neuropathy treated with amytriptyline and fluphenazine. JAMA 1977; 238: 2291-2292.

29. Mendel CM, Klein RF, Chappell DL, et al. A trial of amytriptyline and fluphenazine in the treatment of painful diabetic neuropathy. JAMA 1986; 255: 637-639. 